\section{Vitamin D testing: three important issues}

In Liverpool we are auditing vitamin D testing and prescribing in primary care, following guidelines issued to GPs in early 2012 to encourage evidenced based testing and prescribing. ${ }^{1}$ Our data indicates that some GPs are testing in an increasingly non-targeted way. GPs in Liverpool ordered over $€ 100000$ worth of vitamin D tests in 2012, over 10 times the amount spent in 2007. Though more people were identified as deficient, the proportion of deficient results identified decreased significantly. We feel guidance from NICE is needed for detection and treatment of vitamin $D$ deficiency in primary care.

We also feel it is high time for universal vitamin D supplementation of pregnant and postnatal women and young children as recommended by Chief Medical Officers. ${ }^{2}$ With our increasingly diverse population in the UK we are very aware that currently some groups are missing out on prevention, and Healthy Start vitamin uptake is very low. In Liverpool we are rolling out universal supplementation out this spring. This should lead to a decrease in vitamin D deficiency, decrease in rickets and decrease in need for testing and high dose prescribing.

Thirdly and very importantly the authors wonder why the use of licensed preparations is so low in primary care. This is because there are no high-dose licensed preparations available for us to prescribe. I have been working with vitamin $\mathrm{D}$ deficient patients for the past 10 years. My experience, as well as that of GP colleagues up and down the country, is that compliance is a big problem with low dose preparations particularly in certain population groups at risk of deficiency. Liverpool has a substantial Somali population with deficiency identified in around $80 \%$ of individuals. ${ }^{3}$ Our experience is that to ensure compliance with treatment in our Somali population we need to give a high loading dose of vitamin $\mathrm{D}$ over a short period of time. There is also no high-dose licensed liquid preparation for children. I note the authors appear to have had some connections with various pharmaceutical companies involved in vitamin D manufacture. It would be excellent to see some high dose preparations licensed for use in the UK.

\section{Katy Gardner,}

GP and Clinical Lead for Vitamin D,

Liverpool, UK.

E-mail: katyagardnerabtinternet.com

Stephen Zhao,

Rheumatology trainee Aintree University Hospital, Liverpool, UK.

\section{REFERENCES}

1. Gardner K. Mersey Cluster - Guidance for Vitamin D Deficiency and Treatment Options. 2012; http://www.northmerseyammc.nhs.uk/Library/ publications/North\%20Mersey\%20Guidance\%20 for $\% 20$ Vitamin $\% 20$ D $\% 20$ Deficiency $\% 20$ FINAL $\% 20$ VERSION\%20feb12.pdf laccessed 5 Feb 2014).

2. Vitamin D - advice on supplements for at risk groups. Department of Health; February 2012; https://wnw.gov.uk/government/publications/ vitamin-d-advice-on-supplements-for-at-riskgroups (accessed 5 Feb 2014).

3. Bunn J, Gardner K, Vitlani K, et al. Vitamin D deficiency in Liverpool Somalis: a significant problem. [abstract]. North West Public Health Conference, Manchester, 17 Sept 2013.

\section{DOI: 10.3399/bjgp14X677400}

\section{Proceed with caution: authors' response}

In the December issue lliffe' assured us that our article anticipatory care of older patients represented the triumph of hope over experience'. ${ }^{2}$ We find this a bewildering claim in view of the extensive research evidence to the contrary. No less than six controlled trials between 1979 and 1993 showed that a programme of care, tailored to the special needs of those in advanced old age, reduced the time spent in institutional care (hospitals and nursing homes). They are referenced in our book. ${ }^{3}$ In addition Beswick in 2008, a much more recent metaanalysis than that cited by lliffe, ${ }^{4}$ has made a thorough appraisal of nearly all the research work done in this field. From 89 studies he showed that interventions reduced the risk of not living at home, of nursing-home and hospital admissions and falls. However death rates were not reduced.
Iliffe completely ignores these objectives in pursuit of his opposing views which may not be comparing like with like and he appears to be suggesting that our claims were exaggerated. In fact our claims are exceedingly modest but very important to vulnerable old people. The object of our proposed anticipatory care models is to target vulnerable and frail subjects. They are then offered more time, care and support from the primary care team and trained volunteers. The aim is to enable them to enjoy the best life possible in each case and to remain active and independent for longer. We think the best measure of improved outcomes is the reduced time spent in institutional care and hospital as bed days. lliffe admits that there is research evidence in support here, together with improved patient morale and (in some papers) reduced mortality. However his negative view of preventive care of vulnerable older patients defies the main body of research findings. They are also overturned by the findings of a recent Care Quality Commission Survey. On 21 November they reported ${ }^{5}$ that, in the past year, no less than 530000 people aged $\geq 65$ years required an emergency admission to hospital for conditions which were preventable. Had the GPs involved run an anticipatory care programme the saving to the Exchequer would have been great. Without appropriate action by government, the RCGP and other medical, social and voluntary organisations, there remains a major cause for concern for the welfare of frail older people within the UK.

\section{David Beales,}

Medical Advisor, Centre for Nutrition and Lifestyle Management, Wokingham, UK. E-mail: dbealeslaheartsandminds.fsnet.co.uk

Alastair Tulloch,

Retired GP, Bicester, UK.

\section{REFERENCES}

1. Iliffe S. Proceed with caution. Br J Gen Pract 2013: 63: 629.

2. Beales $D$, Tulloch $A$. Community care of older people: a cause for concern. Br J Gen Pract 2013; 63: 549-550.

3. Beales D, Denman M, Tulloch A. Community care of older people. Abingdon: Radcliffe Medical Press, 1998.

4. Beswick AD, Rees K, Dieppe P, et al. Complex interventions to improve physical function and maintain independent living in elderly people: 